\title{
Análisis de la percepción de la exposición a riesgos ambientales para la salud, en dos poblaciones infantiles, mediante la elaboración de dibujos
}

\author{
Analysis of the exposure perception to environmental \\ health risks, in two children populations, by means of \\ the elaboration of drawings
}

Rocío Torres-Nerio ${ }^{1}$, Gabriela Domínguez-Cortinas², Anuschka van't Hooft 3 , Fernando Díaz-Barriga Martínez4, Ana Cristina Cubillas-Tejeda ${ }^{5}$

${ }^{1}$ Estudiante de Doctorado en Ciencias Ambientales, Programa Multidisciplinario de Posgrado en Ciencias Ambientales, Universidad Autónoma de San Luis Potosí (UASLP), México. pmpca_rtorres@yahoo.com.mx

${ }^{2}$ Doctora en Ciencias Ambientales, Programa Multidisciplinario de Posgrado en Ciencias Ambientales, Universidad Autónoma de San Luis Potosí (UASLP), México. gdomcortinas@yahoo.com

$3^{3}$ Doctora en Antropología, Universidad de Leiden, Holanda. ProfesoraInvestigadora, Coordinación de Ciencias Sociales y

Humanidades, Universidad Autónoma de San Luis Potosí (UASLP), México.

avanthooft@uaslp.mx

${ }^{4}$ Doctor en Biología Celular, Centro de Investigación y de Estudios Avanzados, Instituto Politécnico Nacional, México. Profesor-Investigador, Responsable del Departamento de Toxicología Ambiental, Facultad de Medicina, Universidad Autónoma de San Luis Potosí (UASLP), México. fdia@uaslp.mx

${ }^{5}$ Doctora en Ciencias Biomédicas Básicas, Facultad de Medicina, Universidad Autónoma de San Luis Potosí (UASLP). ProfesoraInvestigadora, Facultad de Ciencias Químicas,

Universidad Autónoma de San Luis Potosí (UASLP), México. acris@uaslp.mx
RESUMEN La exposición a contaminantes ambientales implica un riesgo para la salud, principalmente para la población infantil. Una estrategia de intervención puede ser un Programa de Comunicación de Riesgos (PCR). Para que un PCR sea efectivo es necesario conocer la percepción de la comunidad sobre la exposición a riesgos ambientales. El conocer la percepción de los niños es fundamental para el diseño de los PCR que serán implementados en cada comunidad. En este trabajo se utilizó el dibujo como una herramienta para conocer la percepción de los niños de una comunidad rural-indígena y de niños de una comunidad urbano-marginada. La actividad consistió en la formulación de dos preguntas, las cuales respondieron los niños por medio de la elaboración de un dibujo. Las preguntas se formularon para conocer la percepción en los escenarios dentro y fuera de la casa. Los resultados obtenidos indicaron que los niños perciben la mayoría de las problemáticas ambientales detectadas con anterioridad por nuestro grupo y se encontraron diferencias por comunidad. Además se encontró que algunos niños percibieron problemáticas que no habían sido detectadas por los investigadores.

PALABRAS CLAVE Salud Ambiental; Percepción; Exposición a Riesgos Ambientales; México.

\begin{abstract}
The exposure to environmental pollutants implies a risk for health, mainly for the children population. A strategy of preventive intervention may be a Risks Communication Program (RCP). In order for a RCP to be carried out in an effective form, it is necessary to know the perception of the community about the exposure to environmental risks. Knowing children perception is essential for designing PCR to be implemented in each community. In this work the drawing was used as a tool to understand the perception of the children from a rural-indigenous community and from a marginalized urban community. The activity consisted on the formulation of two questions, which children answered sketching a drawing. The questions were formulated to know their perception in two sceneries: inside and outside their home. The obtained results indicated that the children perceive most of the environmental issues previously detected by our group and there were some differences between communities. In addition, it was found that some children perceived problems that had not been identified by the researchers.
\end{abstract}

KEY WORDS Environmental Health; Perception; Environmental Exposure; Mexico. 


\section{INTRODUCCIÓN}

La salud ambiental es una disciplina que evoluciona a partir de la salud pública para prevenir, investigar y atender, los efectos en salud en aquellas comunidades que han sido afectadas por factores ambientales y factores que incrementan la vulnerabilidad de las poblaciones. (1)

Una buena salud ambiental supone una buena calidad de vida bajo un enfoque ecosistémico; esto es, que el ser humano debe ser tomado en cuenta como un participante más de todo un ecosistema. En consecuencia, los factores ambientales que pueden afectar a la población no se reducen a las sustancias químicas, físicas o biológicas que directamente pueden afectar a la salud, sino también, a aquellos factores que al afectar a todo el ecosistema, afectan la calidad de vida (2).

La vulnerabilidad de la población está determinada por factores extrínsecos asociados a aspectos sociodemográficos, como la inequidad, la pobreza, las prácticas culturales, el nivel de educación, los riesgos por la exposición a contaminantes ambientales, las alteraciones ocasionadas por los cambios climáticos, entre otros (1). La participación del ambiente en la salud ha sido analizada por la Organización Mundial de la Salud (OMS) (3). De acuerdo al estudio de PrüssÜstün y Corvalán (4) se estimó que en todo el mundo el $24 \%$ de la carga de morbilidad (años de vida sana perdidos) y aproximadamente el $23 \%$ de todas las defunciones (mortalidad prematura) eran atribuibles a factores ambientales. En los niños de 0 a 14 años, el porcentaje de muertes que podían atribuirse al medio ambiente era de hasta un 36\%. Entre las enfermedades con la mayor carga absoluta atribuible a factores ambientales modificables figuraron: la diarrea, las infecciones de las vías respiratorias inferiores y el paludismo. Asimismo ha sido reportado que en países en desarrollo, más de la tercera parte de la carga de enfermedad tiene su origen en problemáticas ambientales; la OMS estima que cerca de tres millones de niños mueren anualmente por causas relacionadas con el ambiente (3).

Por otro lado, si se considera la susceptibilidad, es decir, la predisposición intrínseca de un individuo a sufrir daño debido a la problemática ambiental, dos condiciones están involucradas: la marginación y la edad. Por lo tanto, los niños aparecen como el sector más susceptible y lo son todavía más si viven en ambientes marginados. Al no ser adultos pequeños, la susceptibilidad se incrementa por varios factores, entre los cuales se destaca su fisiología, ya que al tener los órganos inmaduros los contaminantes actúan con mayor toxicidad, además de sus actividades lúdicas, sus demandas para desarrollarse y crecer en cuanto a ingesta de agua y alimentación y su incapacidad para alejarse del peligro (3). Lo anterior conlleva a que exista dependencia del niño por el adulto, por lo que la mayoría de las veces se realizan programas preventivos que se enfocan principalmente a los adultos, los cuales muchas veces no son efectivos en los niños.

Una alternativa de los programas preventivos son los llamados Programas de Comunicación de Riesgos (PCR), entendiendo la Comunicación de Riesgos (CR) como un proceso de interacción e intercambio de información y opiniones entre individuos, grupos e instituciones, que involucra mensajes múltiples acerca de la naturaleza del riesgo y otros mensajes (no estrictamente relacionados con el riesgo) que expresan preocupaciones, opiniones y reacciones a los mensajes sobre el riesgo o a los arreglos legales e institucionales para su manejo $(5,6)$. Se han propuesto ocho pasos básicos para el desarrollo de un PCR (7):

a) evaluación del riesgo para la salud;

b) establecimiento de objetivos;

c) evaluación de la audiencia blanco;

d) evaluación del contexto sociocultural;

e) selección del enfoque;

f) construcción de las comunicaciones;

g) puesta en operación del PCR;

h) evaluación de los efectos.

Al realizar un PCR, se debe tomar en cuenta que la noción de riesgo no significa lo mismo para todas las personas y que todo riesgo tiene que abordarse dentro de un contexto social, cultural y económico. La idea que tienen las personas sobre algún riesgo se basa en la diversidad de información sobre los factores de riesgo (a veces denominados peligros), así como sobre sus beneficios y contextos. En este punto es relevante 
hacer una diferencia entre los conceptos de peligro y riesgo. El peligro es definido como un acto o fenómeno que presenta un daño potencial para alguna persona o cosa. El grado de daño que podría resultar del peligro se refiere como su "magnitud" e incluye el número de personas o cosas expuestas y la gravedad de la consecuencia. Por otro lado, el riesgo es definido como la cuantificación de un peligro en términos de la probabilidad de que ocurra el daño o bien los resultados indeseados (7).

Sin embargo, el riesgo no depende solo del cálculo de probabilidades, sino de los contextos sociales y culturales. De modo análogo, la percepción de los riesgos para la salud está enraizada en los distintos entornos económicos, sociales y culturales (8). En este sentido se destacan los análisis de riesgo y cultura y la aceptabilidad del riesgo, realizados por Douglas y Wildavsky. Según estos autores, las personas actúan según parámetros socialmente aceptados, más que por conocimiento de los riesgos. Así, la percepción del riesgo es una categoría social, efecto de la interacción entre miedo y confianza. Las personas reciben la información, y sus valores se forjan en función de su experiencia pasada y de su nivel de conocimientos. Mediante la organización de todos esos conocimientos, que empieza en la primera infancia, los individuos perciben y dan sentido al mundo en que viven (9). Cada sitio contaminado es distinto, pues está formado por personas distintas; cada cultura ve el mundo con su visión propia, por lo que cada PCR debe ser diseñado bajo las particularidades del problema ambiental y de su contexto social para que sea exitoso (7). Parte del éxito de un PCR depende en gran medida de que se involucre a la comunidad desde un inicio, y una manera de involucrarla es analizando inicialmente la percepción que tiene frente a un riesgo para la salud $(6,7,9,10)$.

En nuestro grupo hemos realizado PCR en sitios mineros (datos no publicados aún), en sitios metalúrgicos (11) y en comunidades marginadas con diversas problemáticas ambientales (datos no publicados aún). Estos programas se han enfocado principalmente a la población infantil, que como ya se mencionó anteriormente, generalmente es la población más susceptible. El objetivo ha sido el de brindarles información que les permita modificar conductas y que de esta manera se logre una disminución de la exposición a los contaminantes ambientales. Además se ha trabajado en forma paralela con los padres y madres y los maestros, ya que al tener ellos un contacto más directo con los niños, pueden reforzar los mensajes proporcionados en el PCR y facilitar el cambio de conductas.

Al comenzar con los primeros proyectos de CR en población infantil, nos enfrentamos al reto de tratar de conocer la percepción que tienen los niños de su entorno. Pero, ¿cómo conocer la percepción que tienen de su entorno? La percepción está ligada tanto a los procesos de reflexión como del lenguaje, por lo que es un elemento básico en el desarrollo cognitivo (12). En la literatura se han descrito diversas técnicas, entre ellas los cuestionarios, las entrevistas con profesores o padres y madres y el dibujo. Nosotros optamos por esta última técnica en virtud de que el niño, a través del dibujo, expresa su sentir individual. Ha sido reportado por varios investigadores que existe un paralelismo entre el desarrollo intelectual del niño y el desarrollo de su dibujo $(13,14)$. Luquet $(15)$ asumió que los dibujos de los niños están basados en un modelo interno mental, por lo que propuso cinco etapas en el desarrollo:

a) Realismo fortuito (18 meses a 2 años de edad): estos primeros garabatos demuestran un incremento en la coordinación ojo-mano.

b) Realismo fallido (2 a 3 años): los garabatos se hacen más reconocibles, pero los niños de esta edad continúan algunas veces con fallas en la coordinación.

c) Realismo simbólico (3 a 4 años): los niños comienzan a poner detalles en sus dibujos y relacionarlos.

d) Realismo intelectual (5 a 7 años): los dibujos en esta etapa contienen elementos que los niños saben que existen, aún y cuando ellos no los han visto. En esta etapa se refleja el impacto de los conocimientos en sus dibujos.

e) Realismo visual (8 años en adelante): los niños comienzan a dibujar desde un punto de vista particular, usan proporciones y muestran relaciones.

Además de lo anterior, varios autores coinciden en que los dibujos infantiles funcionan como una "ventana" hacia sus pensamientos y 
sentimientos, principalmente porque reflejan una imagen de sus propios mundos pese a estar en cualquier lugar (16-18). El dibujo es una herramienta fácil para reunir información de y sobre los niños y tiene muchas ventajas, ya que los niños tienden a disfrutar la actividad de dibujar sin mostrar ninguna señal de tensión (19). De acuerdo a Chambers, los dibujos evitan las barreras lingüísticas y permiten la comparación entre grupos de diferentes lenguas y habilidades (20). Existen estudios de Barraza y de Slusarska que explican que el dibujo infantil es una herramienta útil y sistemática para evaluar la percepción de los niños y sus actitudes hacia el medio ambiente, mostrando un modo de lenguaje artístico $(21,22)$. Considerando que la técnica del dibujo se define como un instrumento proyectivo, es decir, que a través de la imagen el niño puede proyectar o expresar desde sensaciones, impresiones, emociones, hasta creencias y conocimientos (23), el tipo de dato que se genera a través de ella es eminentemente de carácter cualitativo. Su análisis e interpretación no se reduce al manejo de las frecuencias y sus posibles correlaciones, sino que exige además de la observación del dibujo en sí mismo, el considerar elementos de referencia tanto del sujeto que lo realiza como de su contexto circundante.

Con base en lo anteriormente expuesto, el objetivo principal del presente trabajo fue el de utilizar el dibujo infantil como herramienta para identificar la percepción de exposición a riesgos ambientales a la salud, en niños de dos comunidades distintas. Además, otro objetivo de este trabajo fue probar la técnica del dibujo como medio de evaluación de cara al diseño de los PCR. Cabe aclarar que aunque la técnica del dibujo tiene su origen en el campo de la psicología, a los efectos de este trabajo se aplicó como una herramienta de apoyo para identificar elementos a través de los cuales se pueda detectar la percepción al riesgo ambiental.

\section{MÉTODOS}

\section{DESCRIPCIÓN DE LAS POBLACIONES}

Se trabajó en una comunidad rural-indígena (Cuatlamayán) y en una comunidad urbanomarginada (Tercera Chica). Ambas pertenecen al estado de San Luis Potosí, México, y se encuentran en riesgo ambiental por diferentes fuentes. Las dos comunidades presentan un bajo nivel de escolaridad $(77 \%$ sin educación posprimaria para ambos casos) y un índice de marginación nivel 5 que corresponde a la categoría de "muy alta marginación" (24). En la mayoría de las familias analizadas, los ingresos semanales por familia/por vivienda son de 0 a 600 pesos mexicanos (0 a 46 dólares estadounidenses) (88\% en Cuatlamayán y $61 \%$ en Tercera Chica). Las dos comunidades muestran un fuerte rezago en el desarrollo social, careciendo de servicios de saneamiento básico como agua entubada, energía eléctrica y principalmente de drenaje, situación que fomenta prácticas insalubres como el fecalismo al aire libre y el consumo de agua de baja calidad.

En las dos comunidades se realizó con anterioridad una evaluación integral de salud infantil, mediante el uso de indicadores sociales, ambientales y de salud, los cuales se seleccionaron a partir de un análisis de indicadores ampliamente utilizados y que permitieran evaluar integralmente factores condicionantes y determinantes de salud en la población infantil $(25,26)$. Para recabar la información de los indicadores sociales y ambientales, se realizó un análisis observacional en cada sitio y se aplicaron cuestionarios previamente validados y estandarizados a los padres y madres (120 en Cuatlamayán y 51 en Tercera Chica) con los cuales se obtuvieron datos generales, nivel de escolaridad, ingresos económicos, hábitos de nutrición, hábitos de higiene, y datos de morbilidad para algunas enfermedades (datos no publicados aún).

Los indicadores de salud como presencia de anemia, exposición a agentes infecciosos y exposición a tóxicos ambientales, se obtuvieron a partir del análisis de muestras biológicas recolectadas en los niños de ambas comunidades (28 niños de Cuatlamayán y 51 niños de Tercera Chica) (datos no publicados aún).

De acuerdo con los resultados obtenidos en los estudios realizados en ambos sitios, las problemáticas relacionadas con la salud ambiental se han divido en dos escenarios: problemáticas "Dentro de la casa" y problemáticas "Fuera de la casa".

Para el caso de Cuatlamayán, en el escenario "Dentro de la casa", las problemáticas detectadas fueron principalmente: 1) la parasitosis 
infantil ( $81 \%$ de los niños estudiados), 2) la exposición a tóxicos del humo de leña ocasionada por el uso de leña para cocinar en fogones tradicionales $(94 \%$ de las familias estudiadas utiliza leña, el $5 \%$ utiliza leña junto con gas y solo el $1 \%$ utiliza solamente gas), 3) la aplicación de plaguicidas caseros ( $56 \%$ de las familias estudiadas) y 4 ) el tabaquismo (4\%).

Con relación al escenario "Fuera de la casa", las principales problemáticas detectadas fueron: 1) la quema de basura (99\% de las familias estudiadas), 2) la parasitosis por la exposición a suelo y agua contaminada con parásitos patógenos (81\% de los niños estudiados) y 3 ) el consumo de alcohol.

Por otro lado, en la comunidad de Tercera Chica, en el escenario "Dentro de la casa" las problemáticas detectadas son similares a las anteriores y corresponden a: 1 ) la parasitosis infantil $(38,2 \%$ de los niños estudiados), 2) el uso de biomasa para cocinar (19\% de las familias estudiadas), 3) la exposición a insecticidas caseros (75\% de las familias) y 4) la práctica de tabaquismo ( $41 \%)$. En el escenario "Fuera de la casa" las problemáticas detectadas fueron: 1) la quema de basura $(69 \%$ de las familias la practican) y 2) la exposición a contaminantes generados por 148 ladrilleras, es decir, fábricas artesanales de ladrillos, que usan hornos generalmente de adobe y en las cuales se emplean como principales combustibles aserrín y basura así como combustóleo. La quema de estos combustibles libera contaminantes a la atmósfera, como monóxido de carbono, dióxido de azufre, hidrocarburos aromáticos policíclicos, plomo, entre otros. Aproximadamente 500 familias de Tercera Chica viven de esta actividad y es alarmante la participación infantil en esta labor (33\% de los niños estudiados) (27). Además la colonia Tercera Chica se encuentra ubicada en una zona de tráfico vehicular.

\section{PROCEDIMIENTO DE APLICACIÓN DE LA HERRAMIENTA DE DIBUJO INFANTIL}

Se trabajó con 12 niños de Cuatlamayán (9 niñas y 3 niños) y 21 de Tercera Chica (11 niñas y 10 niños), todos cursando la primaria, y se contó con la previa autorización de los padres y madres para participar de manera voluntaria en la actividad. Como se mencionó anteriormente, exis- te una evolución cronológica en el desarrollo de los dibujos de los niños, por lo que un factor que puede incidir de manera importante en la calidad de los dibujos es la edad de los niños, ya que, por lo general, los de menor edad (menores de 5 años) tienden a realizar dibujos que adolecen de definición de sus imágenes e ideas y muestran una tendencia hacia elementos imaginativos-figurativos (15). Asimismo, el desarrollo cognitivo atraviesa por una secuencia de etapas no solo cronológicas sino de índole psicológico que van desde lo sensorial, hasta el desarrollo de operaciones concretas y formales (23). Por esta razón, en el presente estudio se trabajó con niños con un rango de edad de 6 a 12 años.

Siguiendo la técnica de Barraza (21), la actividad consistió en el planteamiento de dos preguntas que los niños tuvieron que contestar a través de la elaboración de un dibujo. Dichas preguntas se diseñaron para conocer la percepción en los escenarios "Dentro de la casa" y "Fuera de la casa". Además se incluyeron las palabras "bien" y "mal" para conocer la percepción positiva y negativa del entorno, con lo que se crearon dos preguntas dobles:

$\rightarrow$ ¿Qué hay dentro de tu casa que te hace bien y qué hay que te hace mal?

$\rightarrow$ ¿Qué hay fuera de tu casa que te hace bien y qué hay que te hace mal?

La actividad se llevó a cabo en cada una de las comunidades de manera independiente. A cada niño y niña se le proporcionó una hoja de papel en blanco, lápices y colores. No se llevó a cabo ninguna discusión con los niños antes de la actividad, excepto la explicación del desarrollo de la misma. Se les permitió hasta un máximo de una hora en una sola sesión. Al término de la actividad se le preguntó a cada niño y niña qué significaba cada elemento dentro del dibujo y se registraron las observaciones correspondientes.

\section{ANÁLISIS DE LOS DIBUJOS}

Para poder explicar el procedimiento de observación y análisis que se aplicó en cada uno de los dibujos, en la Figura 1, que corresponde a la situación "Dentro de la casa", se muestra un 


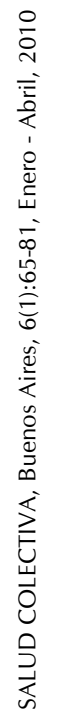

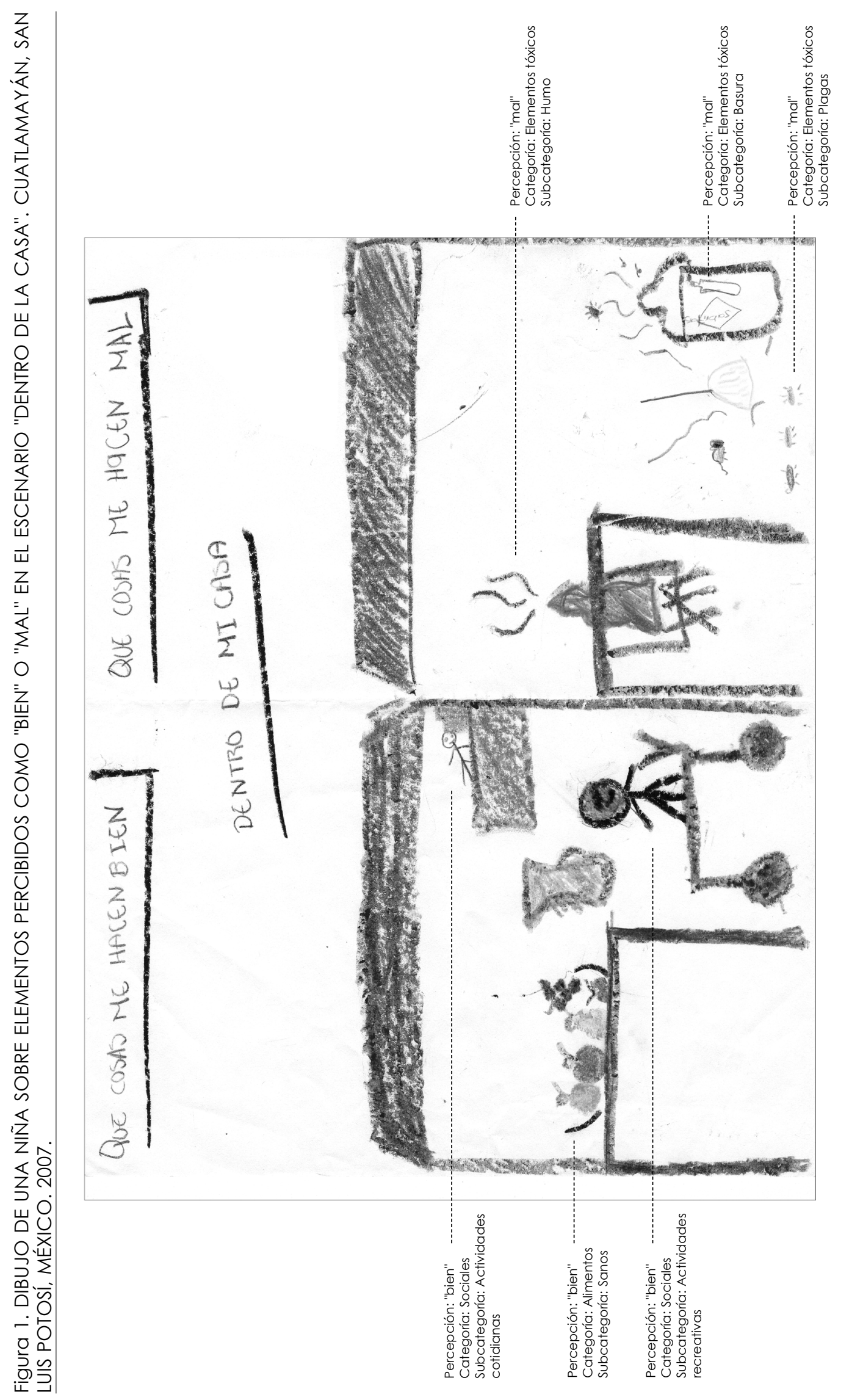


ejemplo a partir del cual se definieron los elementos dibujados que posteriormente conformaron las categorías. Como se observa en el ejemplo, los elementos del dibujo están claramente diferenciados y la respuesta de la niña es congruente con la lógica de las instrucciones dadas. En principio, se muestra que la secuencia en que están ubicados los aspectos que se refieren a la percepción de "bien" y a la percepción de "mal" se colocan a la izquierda y a la derecha respectivamente. Por lo tanto la clasificación y descripción de los elementos se capta con facilidad, gracias a este orden. Es así que, dentro de la percepción de elementos que hacen "bien" se incluyen aspectos relacionados con alimentos sanos y aspectos relacionados con cuestiones sociales (actividades cotidianas, como dormir; actividades recreativas, como jugar). Para el caso de la perspectiva de la niña sobre los elementos que hacen "mal", se pueden encontrar aspectos como elementos tóxicos (humo, basura y plagas, siendo estos últimos representados con ratones, cucarachas y moscas). El ejercicio anterior se realizó para cada uno de los dibujos, fue así como se agruparon y clasificaron los diferentes elementos dibujados, tanto por su frecuencia, como por la naturaleza de su significado.

\section{RESULTADOS}

Al llevar a cabo el análisis de cada uno de los dibujos de la manera descrita anteriormente, se establecieron cuatro categorías principales para clasificar los elementos encontrados en los dibujos:

1) Ambiente

2) Elementos Tóxicos

3) Alimentos

4) Sociales

A su vez, cada categoría se dividió en subcategorías. Para comprender mejor cómo se distribuyeron los elementos encontrados en los dibujos, con relación a las preguntas formuladas, en la Figura 2 se muestran las categorías y subcategorías señaladas anteriormente para los escenarios "Dentro de la casa" y "Fuera de la casa", y para las percepciones de "bien" y "mal".
Como se indicó en la metodología, en el presente estudio se trabajó con niños y niñas con un rango de edad de 6 a 12 años. En ambas comunidades, solo tres tenían menos de 8 años, por lo que no se analizaron los dibujos por grupos de edad, pues el total de niños y niñas para cada comunidad es muy pequeño; sin embargo, consideramos interesante el poder hacer este análisis en estudios posteriores.

Con relación a los resultados obtenidos en la población de Cuatlamayán y Tercera Chica, en el Cuadro 1 se muestran los porcentajes de niños y niñas que dibujaron algún elemento dentro de cada categoría y subcategoría, correspondientes a los dos diferentes escenarios "Dentro de la casa" y "Fuera de la casa", diferenciados además por las percepciones de "bien" y "mal". Es importante señalar que los resultados se expresan en porcentajes, ya que como existe un número diferente de niños en las dos comunidades, de esta manera se aprecian mejor las diferencias.

Como se muestra en el Cuadro 1, en el escenario "Dentro de la casa" y en la percepción "bien", el 58,3\% de los niños y niñas de Cuatlamayán dibujaron elementos dentro de la categoría Alimentos sanos; y el 50\% dibujó elementos de la categoría Sociales, principalmente dentro de la subcategoría Actividades cotidianas. En lo que se refiere a la percepción "mal", el 50\% de los niños y niñas dibujaron elementos dentro de la categoría Elementos tóxicos, predominando las subcategorías de humo, basura y agua contaminada. Por otro lado, en el escenario "Fuera de la casa" y en la percepción "bien", el 83,3\% de los niños y niñas dibujaron elementos dentro de la categoría Ambiente, predominando las subcategorías Flora, Cuerpos de agua y Fauna. Con relación a la percepción "mal", el 66,6\% dibujó elementos dentro de la categoría Ambiente, predominando las subcategorías Clima y Componentes del cielo; sin embargo no existe un claro predominio de alguna de las categorías y subcategorías.

En cuanto a los resultados obtenidos en el grupo infantil de la comunidad de Tercera Chica, como se puede observar en el Cuadro 1, en el escenario "Dentro de la casa" y en la percepción "bien", de forma similar a los resultados obtenidos en Cuatlamayán, existió un predominio en la categoría Alimentos sanos, ya que el $75 \%$ de los niños y niñas dibujaron elementos dentro de esta. En 


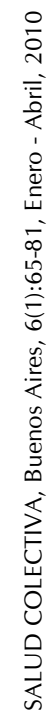
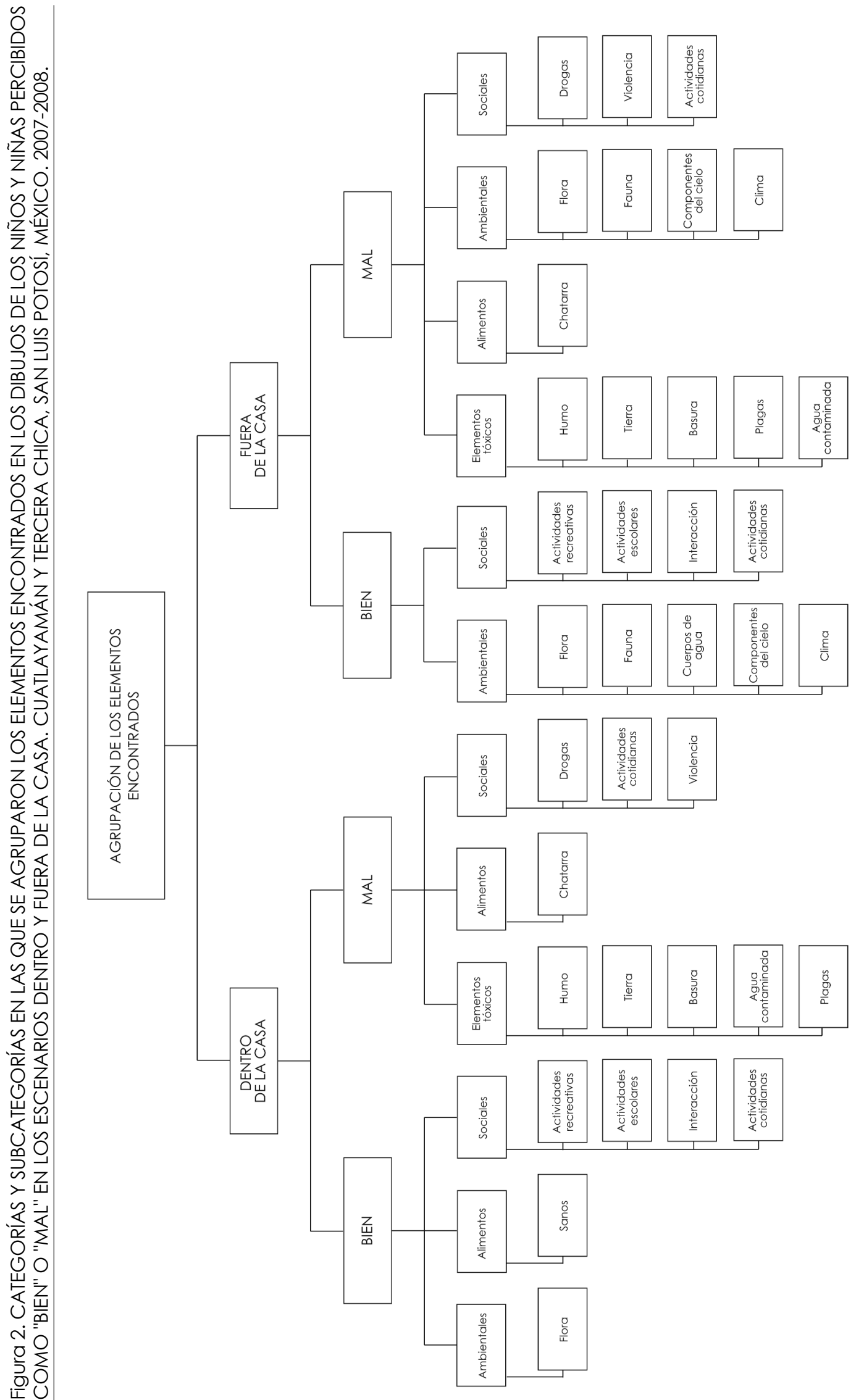

\begin{tabular}{l}
$\frac{0}{0}$ \\
$\frac{0}{0}$ \\
$\frac{0}{0}$ \\
$\frac{0}{0}$ \\
$\frac{0}{0}$ \\
$\frac{0}{0}$ \\
$\frac{0}{0}$ \\
$\frac{0}{4}$ \\
0 \\
$\frac{0}{0}$ \\
\hline
\end{tabular} 
cuanto a la percepción "mal", la mayoría de los niños y niñas dibujaron elementos dentro de la categoría Sociales, subcategoría Actividades cotidianas, seguida de la categoría Alimentos chatarra. En el escenario "Fuera de la casa" y en la percepción "bien", el 47,6\% dibujó elementos en la categoría Ambiente. En cuanto a la percepción "mal", solo el $23,8 \%$ de los niños y niñas dibujaron elementos en la categoría de Ambiente y el 57,1\% dibujó elementos dentro de la categoría Sociales, con un predominio en la categoría Actividades cotidianas, seguida de la subcategoría Violencia.

Para dejar más claro los elementos que dibujan los niños y niñas de acuerdo a su percepción, se muestran dos ejemplos de dibujos en los que se puede apreciar lo que se percibe como "bien" o "mal" en el escenario "Dentro de la casa". La Figura 3, corresponde al dibujo de una niña de Cuatlamayán, y la Figura 4 corresponde al dibujo de una niña de Tercera Chica. En estos dibujos se puede detectar la diferencia entre los elementos dibujados por el grupo infantil de cada comunidades. La niña de Cuatlamayán (Figura 3) dibuja elementos dentro de la categoría Alimentos y dentro de las categorías Ambiente y Sociales, tanto para la percepción "bien" o "mal". Sin embargo, en el dibujo de la niña de Tercera Chica (Figura 4), los elementos encontrados corresponden únicamente a la categoría Alimentos, ya sea sanos, para el caso de la percepción "bien", o chatarra, en la percepción "mal". Por otro lado, en las Figuras 5 y 6 se muestran dos ejemplos de dibujos para el escenario "Fuera de la casa", uno de cada población. En estos ejemplos los elementos encontrados, para lo que los niños y niñas perciben como "bien" o "mal", son diferentes en ambos dibujos. Cada niño o niña dibuja los elementos que puede apreciar en la comunidad donde vive. La niña de Cuatlamayán, que es una comunidad rural-indígena, dibuja elementos relacionados con el medio ambiente, por ejemplo, árboles, animales, cuestiones climáticas; los cuales muestran la diversidad del medio ambiente que existe fuera de su casa y cómo percibe que algunos elementos pueden hacerle bien y otros mal. Sin embargo para la niña de Tercera Chica, que es una comunidad urbanomarginada, los elementos encontrados muestran la poca diversidad del ambiente en el que vive, y además se observa que sí percibe como algo dañino la existencia de ladrilleras fuera de su casa.
Aunque no fue el objetivo del trabajo determinar diferencias estadísticas, ya que el número total de niños y niñas en cada comunidad es pequeño, se realizó la prueba estadística de Fischer y Yates, y se encontró que en el escenario "Dentro de la casa", en la percepción "mal", existe una mayor frecuencia de elementos dibujados dentro de la categoría Elementos tóxicos por los niños y niñas de Cuatlamayán en comparación con los de Tercera Chica $(p=0,026)$. Dentro de esta misma categoría, pero en el escenario "Fuera de la casa", también se observó una tendencia de mayor frecuencia de elementos dibujados por el grupo infantil de Cuatlamayán $(p=0,06)$. Además, se encontró que el grupo infantil de Cuatlamayán dibuja más elementos en la categoría Ambiente, en el escenario "Fuera de la casa", los cuales consideran un riesgo $(p=0,0047)$. De igual manera, en esta categoría existe una tendencia de mayor frecuencia de elementos que los niños y niñas de Cuatlamayán consideran como benéficos $(p=0,06)$.

Para diseñar un PCR exitoso, es importante considerar los riesgos para la salud percibidos por los miembros de la comunidad, junto con los riesgos detectados por los investigadores, por lo que en el Cuadro 2 se muestra un compendio de las problemáticas detectadas anteriormente por nuestro grupo en ambas comunidades, la percepción de los niños y niñas, junto con las subcategorías extraídas de los dibujos de los niños y niñas, las cuales están relacionadas con dichas problemáticas. Es importante señalar que en este Cuadro también se muestran las problemáticas no detectadas por nuestro grupo, pero que sí fueron detectadas por los niños y niñas al percibirlas en su entorno.

\section{DISCUSIÓN Y CONCLUSIONES}

Al analizar los resultados obtenidos en el presente estudio, se puede concluir que el dibujo infantil es una herramienta útil para analizar la percepción de riesgos, ya que los dibujos realizados por los niños nos permitieron conocer la percepción o no percepción de los niños y niñas de cada comunidad, en relación con las problemáticas que implican un riesgo para la salud. Esta técnica nos permitió además 
Cuadro 1. DISTRIBUCIÓN PORCENTUAL DE LOS ELEMENTOS PERCIBIDOS COMO "BIEN" O "MAL" EN LOS ESCENARIOS DENTRO Y FUERA DE LA CASA, POR LOS NIÑOS Y NIÑAS DE CUATLAMAYÁN Y TERCERA CHICA, SAN LUIS DE POTOSÍ, MÉXICO. 2007-2008.

\begin{tabular}{|c|c|c|c|c|}
\hline \multirow{3}{*}{$\begin{array}{l}\text { TIPO DE PERCEPCIÓN, } \\
\text { CATEGORÍA Y SUBCATEGORÍA }\end{array}$} & \multicolumn{2}{|c|}{ CUATLAMAYÁN $(n=12)$} & \multicolumn{2}{|c|}{ TERCERA CHICA $(n=21)$} \\
\hline & "Dentro de la casa" & "Fuera de la casa" & "Dentro de la casa" & "Fuera de la casa" \\
\hline & $\%$ & $\%$ & $\%$ & $\%$ \\
\hline
\end{tabular}

PERCEPCIÓN "BIEN"

AMBIENTE

Flora

Fauna

Cuerpos de agua

Componentes del cielo

Clima

ALIMENTOS

Sanos

58,3

83,3

SOCIALES

Actividades recreativas

$\begin{array}{rrrr}2 & 16,7 & 3 & 25,0 \\ 1 & 8,3 & 1 & 8,3 \\ 1 & 8,3 & 1 & 8,3 \\ 6 & 50,0 & 2 & 16,7\end{array}$

Actividades cotidianas

$\begin{array}{cccc}- & - & 10 & 83,3 \\ - & - & 4 & 33,3 \\ - & - & 6 & 50,0 \\ - & - & 2 & 16,7 \\ - & - & 2 & 16,7\end{array}$

$\begin{array}{rrrr}1 & 4,8 & 6 & 28,6 \\ - & - & - & - \\ - & - & 1 & 4,8 \\ - & - & 7 & 33,3 \\ - & - & 1 & 4,8\end{array}$

Actividades escolares

Interacción

PERCEPCIÓN "MAL"

ELEMENTOS TÓXICOS

Humo

Polvo o tierra

Basura

Plagas

Agua contaminada

AMBIENTE

Flora

Fauna

Componentes del cielo

Clima

ALIMENTOS

Chatarra

SOCIALES

Actividades cotidianas

Violencia

Drogas

$\begin{array}{rrrr}5 & 41,7 & 4 & 33,3 \\ 1 & 8,3 & 3 & 25,0 \\ 2 & 16,7 & 4 & 33,3 \\ - & - & 3 & 25,0 \\ 2 & 16,7 & 1 & 8,3 \\ & & & \\ 1 & 8,3 & 2 & 16,7 \\ 1 & 8,3 & - & - \\ - & - & 4 & 33,3 \\ - & - & 5 & 41,7\end{array}$

$16 \quad 76,2$

$\begin{array}{rrrr}4 & 19,0 & 3 & 14,3 \\ 3 & 14,3 & 1 & 4,8 \\ 2 & 9,5 & 2 & 9,5 \\ 4 & 19,0 & 4 & 19,0\end{array}$

Fuente: Elaboración propia. 
encontrar elementos para sustentar el diseño adecuado de un PCR para cada comunidad; y tiene como ventajas que es poco costosa y divertida para el grupo infantil. En el ámbito de salud, la técnica del dibujo se ha utilizado para el diagnóstico de migraña obteniendo como resultado que el "diagnóstico artístico" se mostró aceptablemente sensible y específico para este fin (28).

La importancia de considerar y analizar la percepción de riesgos para la salud, en los miembros de la comunidad en la cual se pretenda realizar un PCR, es relevante para que los mensajes sobre los riesgos puedan Ilegar a todos. Cada persona percibe los riesgos de manera individual, y la percepción depende de varios factores. Los estudios empíricos sobre la percepción individual de los riesgos tuvieron su origen principalmente en los estudios psicológicos realizados en EE.UU. Un primer descubrimiento importante fue una serie de estrategias y reglas mentales, lo que se entiende por heurística, de las que se sirven las personas para comprender los riesgos (9). En este sentido se puede afirmar que el proceso de evaluación y gestión de los riesgos es de naturaleza científica, y que en la percepción pública de los riesgos intervienen factores sociales, psicológicos y políticos, entre éstos: valores, creencias, costumbres, género, edad, lazos afectivos y confianza, nivel sociocultural y nivel socioeconómico. Por lo tanto, es importante que al promover estrategias de intervención para reducir los riesgos a la salud, se comprenda la diferente percepción que el público general y los profesionales de la salud tienen de esos riesgos $(9,10)$.

En el presente estudio se confirmó que los factores mencionados anteriormente pueden influir en la percepción de riesgos para la salud, ya que se observaron diferencias en las problemáticas detectadas por el grupo infantil de las dos comunidades. Como se muestra en el Cuadro 2, los niños y niñas de Cuatlamayán (comunidad rural-indígena), sí percibieron algunas problemáticas detectadas por nuestro grupo "Dentro de la casa" y todas las problemáticas detectadas "Fuera de la casa". Sin embargo, los niños y niñas de Tercera Chica (comunidad urbano-marginada) no percibieron ninguna de las problemáticas detectadas por nuestro grupo en el escenario "Dentro de la casa", pero sí percibieron como algo que les hace "mal", el humo generado por los automóviles y las ladrilleras "Fuera de la casa". Los riesgos que no se percibieron en ambas comunidades fueron las parasitosis, el uso de plaguicidas y el tabaquismo. Es de suma importancia observar que en ambas comunidades el grupo infantil percibió la violencia tanto fuera como dentro de sus hogares, problemática que no había sido detectada por nuestra parte. Esta problemática debe analizarse con más profundidad en ambas comunidades para determinar de qué manera se incluye en los PCR que se diseñen.

No solo algunos riesgos ambientales fueron percibidos por los niños y niñas que participaron en este trabajo. Los dibujos mostraron que también existe percepción hacia aspectos sociales como el consumo de alcohol. Tal y como se puede observar en el Cuadro 1, el 33,3\% del grupo infantil de Cuatlamayán dibujó esta problemática (Drogas) en el escenario "Fuera de la casa". En el caso de la comunidad de Tercera Chica, en los estudios previos realizados por nuestro grupo no se consideró el alcoholismo como una problemática social; además los niños y niñas no percibieron este riesgo. Sin embargo, actualmente se cuenta con información cualitativa preliminar que permite aseverar que los niños y niñas de esta comunidad conviven de manera frecuente con esta problemática, tanto, que quizás ya no lo perciban como un riesgo. Por esta razón antes de diseñar el PCR se analizará con más detenimiento el alcoholismo en Tercera Chica. Por el contrario y como se señaló anteriormente, los niños y niñas de Tercera Chica sí perciben como riesgo actos de violencia y delincuencia, tales como golpear, robar e incluso hasta matar con armas como pistolas o navajas.

Existen otros aspectos relevantes en los elementos encontrados en ambas poblaciones. Llama la atención el modo en que, de acuerdo al contexto sociocultural en el que se encuentran, el grupo infantil percibe de forma distinta lo que les rodea. Como una muestra de ello, se encontró que dentro de la categoría Sociales, en el escenario "Dentro de la casa", existen dibujos de televisores: mientras que los niños y niñas de Cuatlamayán lo perciben como "bien", el grupo infantil de Tercera Chica lo percibe como "mal". Este hallazgo puede atribuirse a la información que reciben por parte de los padres, los cuales quizás en una comunidad urbana (Tercera Chica), 
Figura 3. DIBUJO DE UNA NIÑA SOBRE ELEMENTOS PERCIBIDOS COMO "BIEN" O "MAL" EN EL ESCENARIO "DENTRO DE LA CASA". CUATLAMAYÁN, SAN LUIS DE POTOSÍ, MÉXICO. 2007.

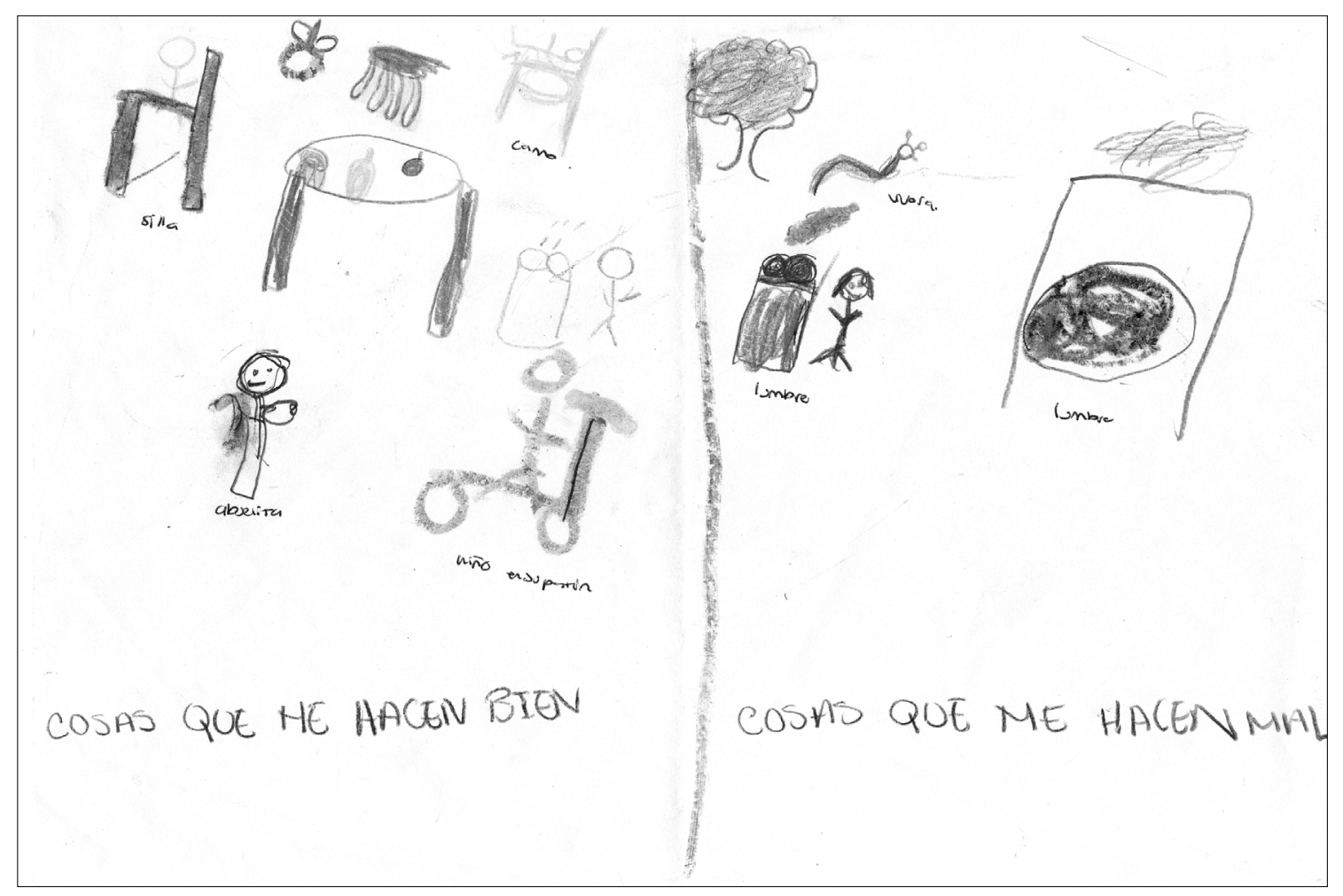

Fuente: Material gráfico obtenido en el trabajo de campo.

Figura 4. DIBUJO DE UNA NIÑA SOBRE ELEMENTOS PERCIBIDOS COMO "BIEN" O "MAL" EN EL ESCENARIO "DENTRO DE LA CASA". TERCERA CHICA, SAN LUIS DE POTOSÍ, MÉXICO. 2007.

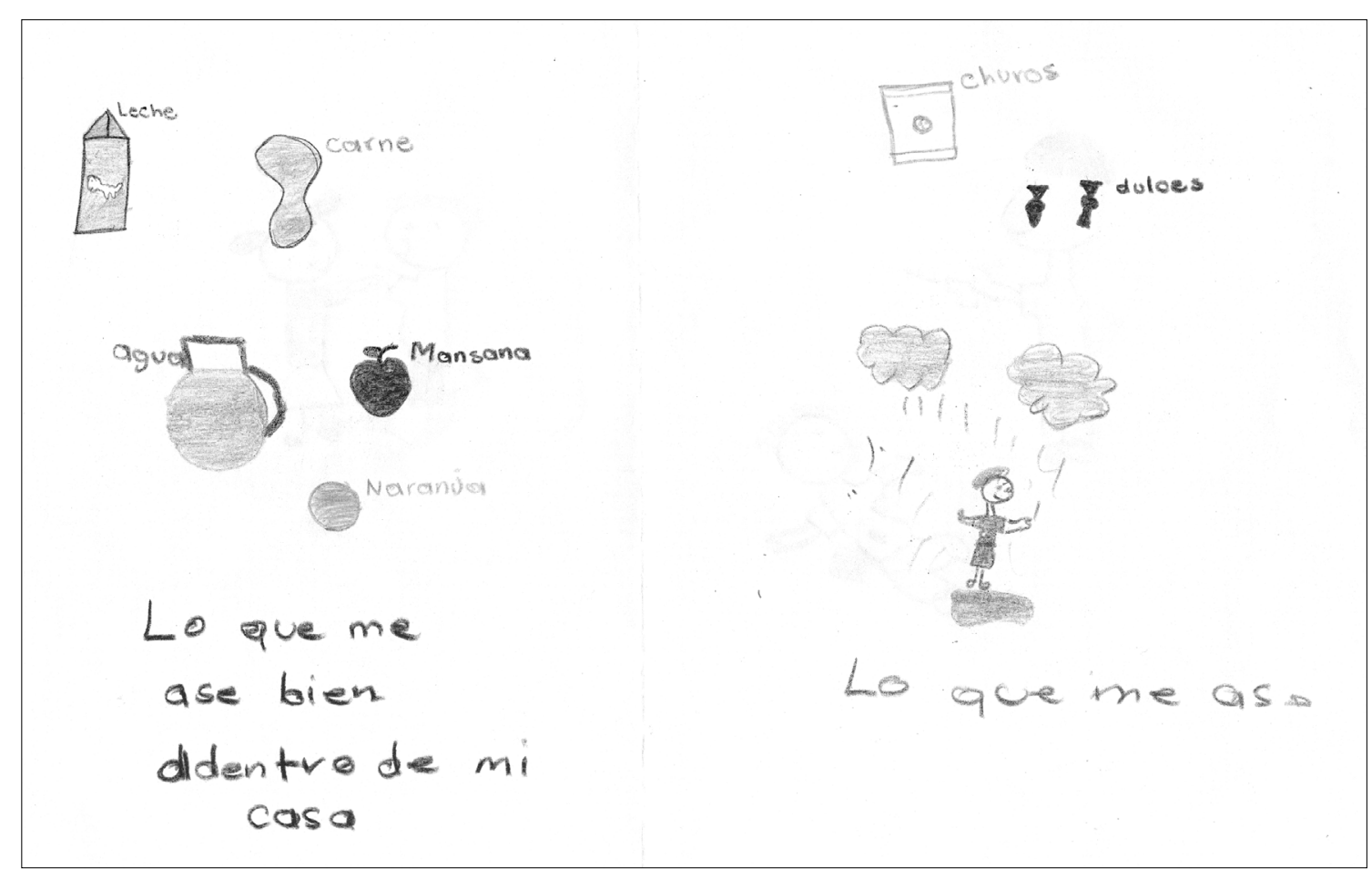

Fuente: Material gráfico obtenido en el trabajo de campo. 
Figura 5. DIBUJO DE UNA NIÑNA SOBRE ELEMENTOS PERCIBIDOS COMO "BIEN" O "MAL" EN EL ESCENARIO "FUERA DE LA CASA". CUATLAMAYÁN, SAN LUIS DE POTOSÍ, MÉXICO. 2007.

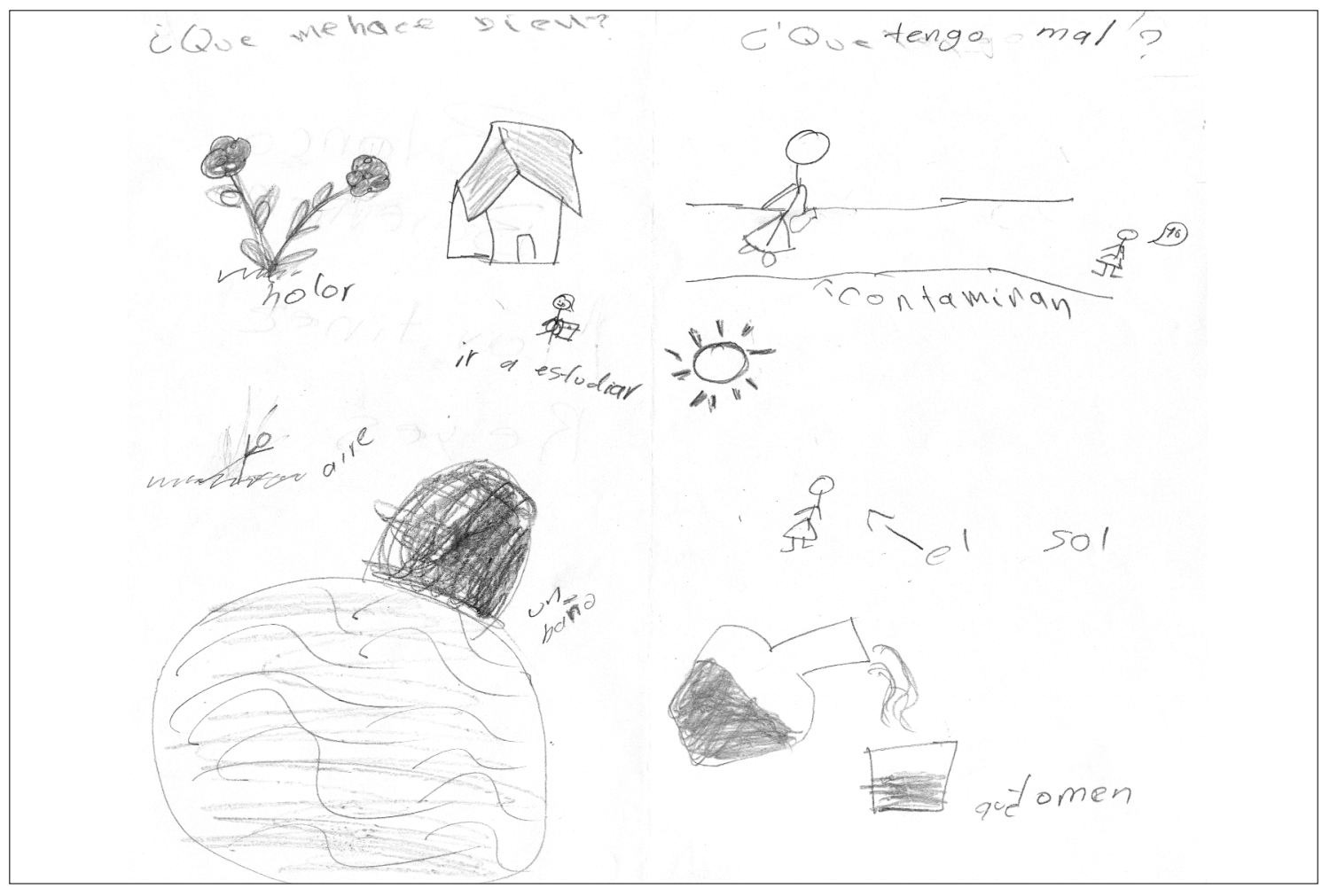

Fuente: Material gráfico obtenido en el trabajo de campo.

Figura 6. DIBUJO DE UNA NIÑA SOBRE ELEMENTOS PERCIBIDOS COMO "BIEN" O "MAL" EN EL ESCENARIO "FUERA DE LA CASA". TERCERA CHICA, SAN LUIS DE POTOSÍ, MÉXICO. 2007.

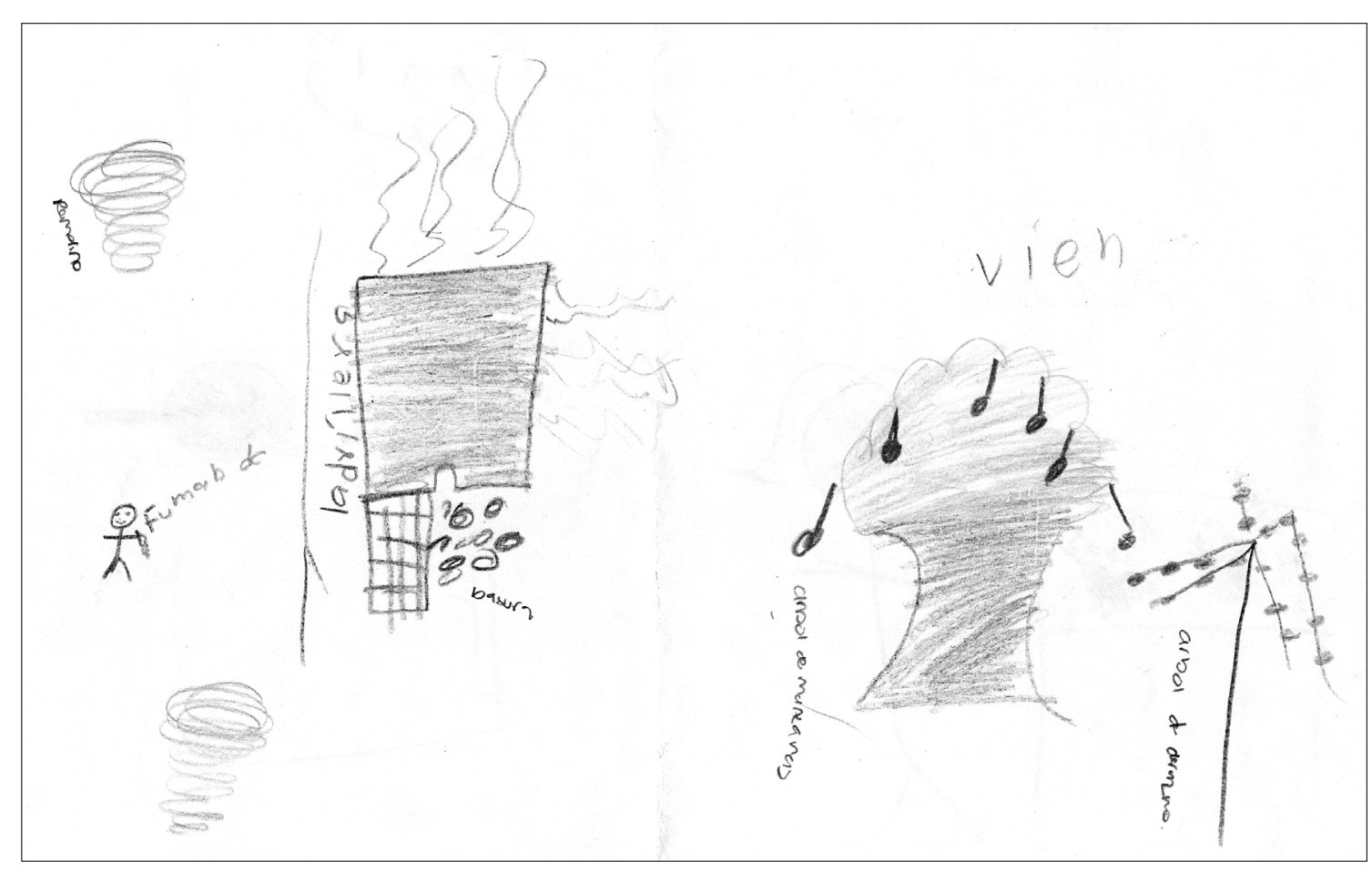

Fuente: Material gráfico obtenido en el trabajo de campo. 
CUadro 2. PROBLEMÁTICAS DETECTADAS POR LOS INVESTIGADORES Y PROBLEMÁTICAS PERCIBIDAS POR LOS NIÑOS Y NIÑAS, SUBCATEGORÍAS RELACIONADAS EN LOS ESCENARIOS DENTRO Y FUERA DE LA CASA. CUATLAYAMÁN Y TERCERA CHICA, SAN LUIS POTOSÍ, MÉXICO. 2007-2008.

\begin{tabular}{|c|c|c|c|c|}
\hline \multirow{2}{*}{$\begin{array}{l}\text { LOCALIDAD Y } \\
\text { ESCENARIO }\end{array}$} & \multicolumn{3}{|c|}{ PROBLEMÁTICAS } & \multirow{2}{*}{$\begin{array}{l}\text { SUBCATEGORÍAS } \\
\text { RELACIONADAS CON } \\
\text { LAS PROBLEMÁTICAS }\end{array}$} \\
\hline & TIPO & $\begin{array}{l}\text { DETECTADAS POR LOS } \\
\text { INVESTIGADORES }\end{array}$ & $\begin{array}{l}\text { PERCIBIDAS POR LOS NIÑOS } \\
\text { Y NINAAS }\end{array}$ & \\
\hline
\end{tabular}

\section{CUATLAMAYÁN}

DENTRO DE LA CASA

FUERA DE LA CASA

Quema de bas
Parasitosis
Alcoholismo
Sociales

Parasitosis

Quema de biomasa

Uso de plaguicidas

Tabaquismo

Sociales

Sociales
Sí

Sí

Sí

Sí

No

Sí

Sí

Sí

No
No perciben parasitosis. Sí perciben agua contaminada

Sí

No perciben plaguicidas.
Sí perciben plagas

No

Sí

Sí

No

Sí

Sí

(n)

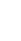

Agua contaminada

Humo

Plagas

Drogas (alcoholismo)

Violencia

TERCERA CHICA

DENTRO DE LA CASA

FUERA DE LA CASA

Parasitosis
Quema de biomasa
Uso de plaguicidas
Tabaquismo
Sociales
Quema de basura
Contaminación del aire
por tráfico vehicular
Ladrilleras
Sociales

No

No

No

No

Sí

No

Sí

Sí

Sí
Violencia

Humo, basura (no los asocian)

Carros emitiendo humo

Humo

Violencia

Fuente: Elaboración propia.

en la cual el uso del televisor ya es algo cotidiano, los niños tienen acceso fácil a él, por lo que si no es restringido su uso por los padres, se puede llegar al abuso y a que descuiden otras actividades. Por otro lado, en una comunidad rural como Cuatlamayán, el uso del televisor es algo novedoso, al que no se tiene acceso fácilmente, por lo que tanto los padres, como los niños y niñas, perciben los aspectos positivos de estos aparatos. Lo mismo sucedió en el caso de la categoría Ambientales, en donde el grupo infantil de Tercera Chica dibujó al sol como algo que les hace "bien" y el de Cuatlamayán lo dibujó como algo que les hace "mal", argumentando que el sol 
no les gusta porque les quema la piel y sienten mucho calor. Quizá esta diferencia se deba a que los niños y niñas de la ciudad generalmente pasan el día dentro de lugares cerrados, como sus escuelas y hogares, y cuando tienen la oportunidad de exponerse por períodos cortos al sol, perciben sus efectos positivos. En el caso de los niños y niñas de una comunidad rural, en la que gran parte del día la pasan en el exterior, sienten más los efectos de una exposición prolongada al sol, por lo que lo perciben y refieren como algo dañino para su salud. Los resultados encontrados en el presente estudio, concuerdan con el estudio realizado por Barraza (21), en el cual se compara la percepción hacia el ambiente entre dos grupos infantiles de diferente país. La conclusión principal que este estudio menciona es que la percepción está mediada por la cultura.

La información obtenida en el presente estudio se tomará en cuenta para el diseño de un PCR que se implementará en un futuro próximo en cada comunidad, en el que se incluirá información sobre los riesgos a la salud detectados con anterioridad por nuestro grupo, pero además se incluirán los riesgos detectados por los niños y niñas y que no habían sido considerados por nuestro grupo. Un reto será hacer que los niños y niñas perciban los riesgos de las problemáticas detectadas por nuestro grupo, pero que ellos actualmente no perciben como un riesgo, por lo que la manera de abordar las problemáticas percibidas y no percibidas dentro de los PCR será diferente. Es de vital importancia conocer la percepción de la población en cuanto a riesgos ambientales, además de sus preocupaciones, para planear PCR que desde un inicio favorezcan la participación comunitaria y que efectivamente permitan lograr cambios de comportamiento en la población infantil. Estos cambios de comportamiento deberán tener como consecuencia la disminución de la exposición a los riesgos ambientales y por lo tanto una repercusión benéfica en la salud de estas poblaciones.

\section{AGRADECIMIENTOS}

Agradecemos el apoyo económico brindado por el Consejo Nacional de Ciencia y Tecnología (CONACyT), clave del convenio FMSLP-2005-CO1-26 (Fondos Mixtos-SLP). Asimismo por el apoyo otorgado a través de la Beca de doctorado, clave de convenio 176783 y a través del Programa de Formación de Doctores, Convenio CONACyT-UASLP 6346805.

Se agradece además la ayuda y colaboración del Dr. Javier Guerra Ruiz-Esparza por proporcionar datos relevantes en esta investigación. Finalmente se agradece de manera muy especial a todos los niños participantes en este estudio.

\section{REFERENCIAS BIBLIOGRÁFICAS}

1. Organización Panamericana de la Salud. Metodologías de evaluación de riesgo y de impacto a la salud en México. [En línea]. México: OPS; 2005 [fecha de acceso 2 de septiembre de 2008]. URL disponible en: http://www.mex.opsoms.org/contenido/metodologia.htm

2. Lebel J. El tema. En: Salud: un enfoque ecosistémico. Canadá: Alfaomega, IDRC; 2005. [En línea]. Canadá: Centro Internacional de Investigaciones para el Desarrollo; 2005 [fecha de acceso 2 de septiembre de 2008]. URL disponible en: http://www.idrc.ca/es/ev-28990-201-1DO_TOPIC.html

3. Organización Panamericana de la Salud. Salud infantil, tóxicos y medio ambiente: riesgos existentes y emergentes. [En línea]. Washington: OPS; 2006 [fecha de acceso 17 de julio de 2008]. URL disponible en: http://www.cepis.opsoms.org/bvsana/matedu/vulnera.pdf 
4. Prüss-Üstün A, Corvalán C. Ambientes saludables y prevención de enfermedades: hacia una estimación de la carga de morbilidad atribuible al medio ambiente. [En línea]. Ginebra: Organización Mundial de la Salud; 2006 [fecha de acceso 7 de agosto de 2008]. URL disponible en: http://whqlibdoc.who.int/publications/2006/9243594206_spa.pdf

5. Curso de autoinstrucción: Comunicación de Riesgos [curso en línea]. Organización Panamericana de la Salud; 2003 [fecha de acceso 12 de mayo de 2007] URL disponible en: http://www.opas.org.br/ambiente/risco/tutorial6/e/temas.html

6. Covello V, Sandmand PM. Risk communication: evolution and revolution. En: Wolbarst $A$, editor. Solutions to an Environment in Peril. Baltimore: John Hopkins University Press; 2001. p. 164-178. [En línea] Princeton: The Peter M. Sandman Risk Communication Website; 2004 [fecha de acceso 17 de mayo del 2008]. URL disponible en: http://www.psandman.com/articles/covello.htm

7. Baker F. Comunicación del riesgo sobre peligros ambientales. En: Taller de comunicación de riesgos. Lima: Cepis; 2001. Anexo 5. [En Línea] OPS, BVSDE [fecha de acceso 14 de agosto de 2009]. URL disponible en: http://www.cepis.org.pe/bvsacd/scan2/037053/ 037053-05-5.pdf

8. Organización Mundial de la Salud. Percepción de los riesgos. En: OMS. Informe sobre la salud en el mundo 2002. Reducir los riesgos y promover una vida sana. Ginebra: OMS; 2002. p. 3150. [En línea] OMS, 2010 [fecha de acceso 14 de agosto de 2009]. URL disponible en: http://www.who.int/whr/2002/en/Chapter3S.pdf

9. Douglas M, Wildavsky A. Risk and culture. An essay on the selection of technical and environmental dangers. Berkeley: University of California Press; 1982.

10. Briceño-León R. Siete tesis sobre la educación sanitaria para la participación comunitaria. Cadernos de Saúde Pública. 1996;12(1):7-30.

11. Torres-Nerio R, Díaz-Barriga Martínez F, Carrizalez-Yañez L, Coronado-Salas C, Nieto Caraveo LM, Moreno Sánchez AR, Barraza Lomelí L, Cubillas-Tejeda AC. Diseño y aplicación de un Programa de Comunicación de Riesgos para la salud ambiental infantil en un sitio contaminado con plomo y arsénico. Ciência \& Saúde Coletiva (en prensa 2010). [Fecha de acceso 5 de marzo de 2010]. URL disponible en: http://www.abrasco.org.br/cienciaesaudecoletiva/artigos/artigo_int.php?id_arti go $=4319$

12. García Luna AM. Definición de percepción. [En línea]. Psicopedagogía, 2008 [fecha de acceso 24 de agosto de 2008] URL disponible en: http://www.psicopedagogia.com/definicion/percepcion

13. Levín R. La escena inmóvil: teoría y clínica psicoanalítica del dibujo. Buenos Aires: Lugar Editorial; 2005.

14. Sáinz Martín A. Teorías sobre el arte infantil: una mirada a la obra de G. H. Luquet. [En línea] Arte, Individuo y Sociedad. 2002;(Supl 1):173-186 [fecha de acceso 24 de agosto de 2008]. URL disponible en: http://dialnet.unirioja.es/servlet/articulo codigo $=2142667$ \&orden $=1$ \&info $=$ link

15. Luquet $\mathrm{GH}$. Les dessins d'un enfant: étude psychologique. París: Feliz Alcan; 1913.

16. Thomas G, Silk A. An introduction to the psychology of children's drawings. Londres: Harvester Wheatsheaf; 1990.

17. Grieve R. Children's awareness. En: Grieve R, Hughes M. Understanding children. Oxford: Basil Blackwell; 1990.

18. Crook CK. Knowledge and appearance. En: Freeman N, Cox M, editores. Visual order. Cambridge: Cambridge University Press; 1985.

19. King LD. Doing their share to save the planet. Children and environmental crisis. New Jersey: Rutgers University Press; 1995.

20. Chambers DW. Stereotypic images of the scientist: the draw-a-scientist test. Science Education. 1983;67(2):255-265.

21. Barraza L. Children's drawings about the environment. Environmental Education Research. 1999;5(1):49-66.

22. Slusarska B, Krajewska-Kutak E, Zarzycka D. Children's perception of the nursing profession in Poland. Nurse Education Today. 2004;24(7):521-529.

23. Fabregat E. El dibujo infantil. El dibujo y la psicología. México: Fernández Editores; 1966.

24. Consejo Nacional de Población. Índice de Marginación Urbana, 2000. [En línea] México: CONAPO; 2002 [fecha de acceso 20 de mayo de 2009]. URL disponible en: http://www.cona- 
po.gob.mx/index.php?option $=$ com_content\&vi ew $=$ article\&id $=130 \&$ Itemid $=208$

25. World Health Organization. Environmental Health Indicators: Framework and Methodologies. Ginebra: WHO; 1999. (WHO/SDE/OEH/99.10).

26. World Health Organization. Environmental Health Indicators: Development of a Methodology for the WHO European Region. [En línea] Copenhague: WHO Regional Office for Europe; 2000 (EUR/00/5026344) [fecha de acceso 20 de mayo de 2009]. URL disponible en: http://www.euro.who.int/document/E71437.pdf
27. Secretaría de Ecología y Gestión Ambiental. Guía para la elaboración de los términos de referencia del parque ladrillero en San Luis Potosí. México: SEGAM; 2004.

28. Mosquera M, Martino G. Diagnóstico por medio del dibujo en niños y adolescentes con migraña. Archivos Argentinos de Pediatría. 2008;106(1):11-18.

\section{FORMA DE CITAR}

Torres-Nerio R, Domínguez-Cortinas G, van't Hooft A, Díaz-Barriga Martínez F, Cubillas-Tejeda AC. Análisis de la percepción de la exposición a riesgos ambientales para la salud, en dos poblaciones infantiles, mediante la elaboración de dibujos. Salud Colectiva. 2010;6(1):65-81.

Recibido el 5 de mayo de 2009

Versión final presentada el 27 de agosto de 2009

Aprobado el 28 de septiembre de 2009 